\title{
Staring at the stars: a case of gastrointestinal basidiobolomycosis from the Indian subcontinent
}

\author{
Nitin Gupta, ${ }^{1}$ Abdul Razik, ${ }^{2}$ Manish Soneja ${ }^{3}$
}

${ }^{1}$ Medicine, All India Institute of Medical Sciences, New Delhi, Delhi, India

${ }^{2}$ Radiodiagnosis, All India Institute Of Medical Sciences, New Delhi, New Delhi, India ${ }^{3}$ Medicine, All India Institute of Medical Sciences, New Delhi, India

\section{Correspondence to} Dr Manish Soneja, manishsoneja@gmail.com

Accepted 23 August 2018

\section{DESCRIPTION}

A 24-year-old male patient from the hot and arid state of Rajasthan, India, presented with low-grade fever, dull aching lower abdominal pain, loss of weight and loss of appetite for 2 years. In addition, he had frequent episodes of colicky abdominal pain and vomiting. $\mathrm{He}$ was evaluated elsewhere prior to presenting at our hospital. A contrast-enhanced computed axial tomography of the abdomen revealed diffuse circumferential thickening of the ileocecal region (figure 1). A fine -needle aspiration cytology revealed features suggestive of non-specific inflammation. He did not respond to multiple courses of antibiotics and was taken up for laparotomy, in which the affected segment of intestine was resected. On gross examination, the resected segment of bowel showed multiple areas of necrosis and small perforations. Histopathological examination (HPE) revealed panmural inflammation of the intestine with eosinophilic microabscesses. Broad aseptate hyphae were noted and reported as mucormycosis. Postoperatively, he was symptomatically better for 1 month, after which, there was a recurrence of fever and abdominal pain. After 2 months of non-resolving complaints, the patient was referred to our hospital. At the time of presentation, his general and systemic examination was normal. His routine haematology and biochemistry evaluation revealed peripheral eosinophilia (total leucocyte count of $6 \times 10^{9} \mathrm{~L}$, eosinophil count of $14.5 \%$ ). The HPE slide was reviewed which revealed multiple broad aseptate hyphae with star-like eosinophilic projections (Splendore-Hoeppli phenomenon) (figure 2). With a provisional diagnosis of basidiobolomycosis, he was started on oral itraconazole. There was complete resolution of symptoms and the patient was asymptomatic after 4 months of therapy.

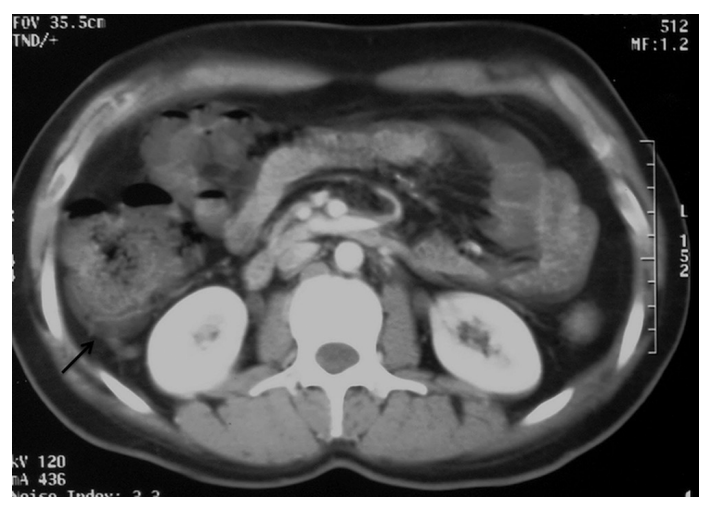

Figure 1 Axial contrast-enhanced CT of the abdomen showing circumferential wall thickening of the cecum (arrow). The thickening shows wall stratification, consistent with inflammatory aetiology.

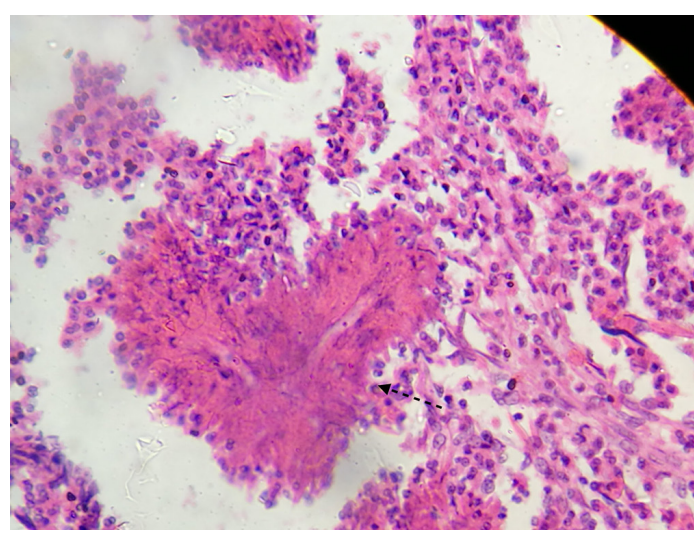

Figure 2 Histopathological section of the resected ileum showing broad aseptate hyphae with SplendoreHoeppli phenomenon (arrow).

Even though Basidiobolus ranarum is endemic to the tropical parts of Asia, America and Africa, it rarely causes clinical disease in humans. The most common clinical presentation is subcutaneous swellings in the extremities or the limb girdle areas in immunocompetent individuals. It can very rarely affect the gastrointestinal tract (small or large intestine) where it manifests as intestinal thickening or masses. ${ }^{1}$ These patients are often misdiagnosed as tuberculosis, malignancy or Crohn's disease. Histopathology (aseptate hyphae with Splendore-Hoeppli phenomenon) with or without culture is required for confirmation. The treatment includes surgery with prolonged course of antifungals

Learning points

In patients presenting with fever and abdominal pain who have imaging findings of intestinal thickening or mass, the common differentials include tuberculosis, malignancy, lymphoma, Crohn's disease and diverticulitis. Basidiobolomycosis should also be kept among the differentials in patients with peripheral eosinophilia coming from hot and arid climatic zones.

- Diagnosis requires culture or demonstration of aseptate hyphae with surrounding eosinophilic projections (Splendore-Hoeppli phenomenon) on histopathological examination. This should be differentiated from mucormycosis which may also rarely involve the gastrointestinal tract and show aseptate hyphae without SplendoreHoeppli phenomenon. 
(itraconazole or amphotericin B). When treated properly, there is a response rate of more than $80 \% .^{2}$ We report this case to highlight a rare manifestation of a rarely diagnosed fungus that often masquerades as infection and malignancy. The awareness of this entity, early clinical suspicion and timely diagnosis can potentially alleviate significant morbidity.

Contributors NG, AR and MS contributed to the planning, concept and design of the paper. NG and MS acquired details of the case and drafted the article. NG, AR and MS revised the article critically. All authors gave final approval of the version published. The authors are in agreement to be accountable for the article and ensure that all questions regarding the accuracy or integrity of the article are investigated and resolved.
Funding The authors have not declared a specific grant for this research from any funding agency in the public, commercial or not-for-profit sectors.

Competing interests None declared.

Patient consent Obtained.

Provenance and peer review Not commissioned; externally peer reviewed.

\section{REFERENCES}

1 Geramizadeh B, Heidari M, Shekarkhar G, et al. Gastrointestinal basidiobolomycosis, a rare and under-diagnosed fungal infection in immunocompetent hosts: a review article. Iran J Med Sci 2015;40:90.

2 Bering J, Mafi N, Vikram HR. Basidiobolomycosis: an unusual, mysterious, and emerging endemic fungal infection. Paediatr Int Child Health 2018;38:81-4.

Copyright 2018 BMJ Publishing Group. All rights reserved. For permission to reuse any of this content visit

http://group.bmj.com/group/rights-licensing/permissions.

BMJ Case Report Fellows may re-use this article for personal use and teaching without any further permission.

Become a Fellow of BMJ Case Reports today and you can:

- Submit as many cases as you like

- Enjoy fast sympathetic peer review and rapid publication of accepted articles

Access all the published articles

Re-use any of the published material for personal use and teaching without further permission

For information on Institutional Fellowships contact consortiasales@bmjgroup.com

Visit casereports.bmj.com for more articles like this and to become a Fellow 